\title{
alelopatia e Homeopatia no Manejo da Tiririca (Cyperus rotundus) ${ }^{1}$
}

\author{
Allelopathy and Homeopathy in the Management of Nutsedge (Cyperus rotundus)
}

\author{
SILVEIRA, H.R.O. ${ }^{2}$, FERRAZ, E.O. ${ }^{3}$, MATOS, C.C. ${ }^{4}$, ALVARENGA, I.C.A. ${ }^{5}$, GUILHERME, D.O. ${ }^{6}$, \\ TUFFI SANTOS, L.D. ${ }^{7}$ e MARTINS, E.R. ${ }^{7}$
}

\begin{abstract}
RESUMO - A tiririca (Cyperus rotundus) é uma espécie daninha de dificil manejo, causadora da redução do estande e do rendimento em plantios comerciais das mais variadas culturas. Devido à sua agressividade, capacidade de reprodução, alta dispersão e rusticidade, seu controle é dificil e oneroso. Objetivou-se com este trabalho avaliar métodos alternativos de controle da tiririca baseados na alelopatia e na homeopatia. No manejo com alelopatia, testaram-se extratos aquosos de feijão-de-porco (Canavalia ensiformes), mucuna-preta (Stizolobium aterrimum), alecrim-pimenta (Lippia sidoides) e capim-limão (Cymbopogon citratus). Com a homeopatia foi utilizada a escala centesimal hahnemanniana, onde se testaram as dinamizações $3 \mathrm{CH}, 6 \mathrm{CH}, 9 \mathrm{CH}$ e $12 \mathrm{CH}$. Ambos os experimentos foram conduzidos em caixas gerbox transparentes, contendo areia grossa lavada, grãos de 1 a $3 \mathrm{~mm}$ de espessura, e 10 tubérculos sadios de tiririca, distribuidos uniformemente ao longo do recipiente. Após a aplicação dos tratamentos, os recipientes foram dispostos em estufa do tipo BOD a $25{ }^{\circ} \mathrm{C}$, com fotoperíodo de 12 horas, onde permaneceram por 15 dias até a avaliação final. O extrato que apresentou o melhor manejo da tiririca foi o de alecrim-pimenta, que diminuiu o percentual de emergência e o vigor das plântulas; o extrato dessa espécie ocasionou maior efeito na redução do comprimento das plântulas de tiririca do que 2,5 kg ha-1 i.a. atrazina - herbicida utilizado para comparação. A homeopatia não apresentou diferença entre as dinamizações, não tendo assim efeito satisfatório no controle da tiririca. Os extratos de capim-limão, mucunapreta e feijão-de-porco não apresentaram efeitos alelopáticos. No entanto, o extrato de alecrim-pimenta é promissor no manejo alternativo de tiririca, sendo necessários novos estudos para elucidação dos princípios químicos envolvidos e da sua real ação no metabolismo da planta.
\end{abstract}

Palavras-chave: alelopatia, extratos aquosos, controle alternativo.

\begin{abstract}
The nutsedge (Cyperus rotundus) is a harmful weed of difficult control, causing reduction of stand and yield of a wide variety of commercial crops. Due to its aggressiveness, reproduction capacity, high dispersion and rusticity, its control is difficult and costly. The aim of this work was to evaluate alternative methods of nutsedge control based on allelopathy and homeopathy. In the management with allelopathy, aqueous extracts of jack bean (Canavalia ensiformes), black velvet bean (Stizolobium aterrimum), rosemary pepper (Lippia sidoides) and lemon grass (Cymbopogon citratus) were tested. With homeopathy, the Hahnemannian centesimal scale was used, testing the $3 \mathrm{CH}, 6 \mathrm{CH}, 9 \mathrm{CH}$ and $12 \mathrm{CH}$ dynamizations. Both experiments were conducted in transparent Gerboxes containing washed coarse sand, 1 to $3 \mathrm{~mm}$ thick grains, and 10 healthy nutsedge tubers, distributed evenly within the container. After the application of the treatments, the containers were placed in a BOD germination chamber at $25{ }^{\circ} \mathrm{C}$ with a 12 hour photoperiod, where they remained for 15 days until the final evaluation. The extract presenting the
\end{abstract}

1 Recebido para publicação em 20.8.2009 e na forma revisada em 3.9.2010.

2 Mestrando em Fisiologia Vegetal, Universidade Federal de Lavras - UFLA, Programa de Pós-Graduação em Fisiologia Vegetal, Caixa Postal 3037, 37200-000 Lavras-MG, <helbert_rezende@yahoo.com.br>; ${ }^{3}$ Mestranda em Fitotecnia, UFLA; ${ }^{4}$ Acadêmico do curso de Agronomia da Universidade Federal de Minas Gerais - UFMG; ${ }^{5}$ Mestrando em Agroecologia, UFMG; ${ }^{6}$ Doutorando em Produção Vegetal pela Universidade Estadual do Norte Fluminense Darcy Ribeiro - UENF; ${ }^{7}$ Professor do ICA/UFMG. Instituto de Ciências Agrárias da UFMG, Av. Universitária, 1000, Caixa Postal 135, 39404-006 Montes Claros-MG.

Planta Daninha, Viçosa-MG, v. 28, n. 3, p. 499-506, 2010 
best nutsedge management was rosemary pepper, which reduced plantlet emergence percentage and vigor, with the extract of this species causing a length reduction in the nutsedge plant higher than that of $2.5 \mathrm{~kg} \mathrm{ha}^{-1}$ a.i. of atrazine, the herbicide used for comparison. The homeopathy treatment did not present a significant difference, not exhibiting the expected effect with its nutsedge control dynamizations. The lemon grass, black velvet bean and jack bean extracts did not present allelopathic effects. However the rosemary pepper extract was found to be promising as a nutsedge alternative management, with further studies being necessary to elucidate the chemical principles involved and its true action in the metabolism of the plant.

Keywords: allelopathy, aqueous extracts, alternative control

\section{INTRODUÇÃO}

A tiririca (Cyperus rotundus) é uma planta daninha de difícil manejo e causadora de prejuízos em diversas culturas comerciais. Os prejuízos decorrem da competição durante todo o ciclo, porém os períodos mais críticos se encontram na fase inicial de desenvolvimento das culturas e nas reformas dos cultivos. Por se tratar de uma espécie perene, pela ampla adaptabilidade a muitos ambientes agrícolas e pela capacidade de se reproduzir sexuada e assexuadamente, a tiririca encontra-se entre as 20 espécies daninhas que mais causam prejuízos no mundo (Panozzo et al., 2009).

Os tubérculos de tiririca atuam como as principais unidades de dispersão ao longo do tempo, permanecendo dormentes no solo por longos períodos. A dormência dos tubérculos causa emergência irregular, contribuindo para a persistência dos propágulos dessa espécie no solo (Jakelaitis et al., 2003).

Uma alternativa que vem sendo estudada, com o propósito de complementar os métodos tradicionais de manejo, minimizando o uso de herbicidas, é a utilização de espécies que liberam substâncias prejudiciais a outras fenômeno conhecido como alelopatia, reduzindo ou até mesmo inibindo totalmente o desenvolvimento de plantas daninhas (Gomide, 1993).

Muitas leguminosas possuem potencialidades alelopáticas (Souza Filho et al., 1997). A parte aérea dessas plantas, seguida das raizes, constitui-se na principal fonte dessas substâncias químicas solúveis em água. A mucuna-preta (Stizolobium aterrimum) e o feijão-de-porco (Canavalia ensiformes) são plantas usadas como adubos verdes que já vêm sendo estudadas no tocante aos seus efeitos alelopáticos em outras plantas há algum tempo, visando ao manejo de plantas daninhas (Souza Filho et al., 1997; Cruz et al., 2002; Balbinot-Junior, 2004; Saito, 2004).

A mucuna-preta exerce forte e persistente ação inibidora sobre a tiririca (Cyperus sp.) e o picão-preto (Bidens pilosa) (Carvalho et al., 2002). A aplicação de extrato aquoso de Mucuna spp. conseguiu suprimir a emergência e o crescimento de plantas de picão-preto (Balbinot Jr., 2004). Isso também foi observado para o feijão-de-porco, que, mesmo em condições de baixa densidade de plantio, apresentou efeito alelopático inibitório sobre a tiririca (Magalhães \& Franco, 1962).

Algumas plantas medicinais mostram em sua composição princípios ativos que podem apresentar efeitos alelopáticos, inibidores ou estimulantes, sobre outras plantas. Para Saito (2004), as espécies que apresentam em sua composição óleos essenciais, como é o caso do capim-limão (Cymbopogon citratus) e do alecrim-pimenta (Lippia sidoides), normalmente são promissoras para o controle de plantas daninhas.

Homeopatia é uma palavra de origem grega que quer dizer "cura pelo semelhante" (homoios $=$ semelhante e pathos $=$ sofrimento, doença). É uma ciência que pode ser aplicada a todos os seres vivos, sejam seres humanos, animais domésticos ou silvestres, vegetais ou microrganismos (Rossi et al., 2004). De acordo com a teoria homeopática, a doença equivale a um desequilíbrio dinâmico, que pode ser auxiliado na sua correção pela utilização de medicamentos previamente experimentados, em doses mínimas, aplicados por provocarem uma sindrome semelhante no organismo, contra a qual este reage simultaneamente à condição inicial, atingindo assim o equilíbrio. Podem-se preparar soluções homeopáticas 
com vegetais objetivando o equilíbrio de seu desenvolvimento no ambiente de cultivo, o que traz menores impactos aos produtores (Rossi et al., 2004).

Neste trabalho, buscou-se estudar métodos alternativos de controle da tiririca com o uso de extratos aquosos de feijão-de-porco, mucuna-preta, alecrim-pimenta e capim-limão e da homeopatia nas dinamizações $3 \mathrm{CH}, 6 \mathrm{CH}, 9 \mathrm{CH}$ e $12 \mathrm{CH}$.

\section{MATERIAL E MÉTODOS}

O presente trabalho foi dividido em dois experimentos: um com extratos de plantas e outro com homeopatia. Os experimentos foram conduzidos no Instituto de Ciências Agrárias da Universidade Federal de Minas Gerais (ICA-UFMG), localizado no municipio de Montes Claros - MG, com altitude de $630 \mathrm{~m}$, latitude de $16^{\circ} 45^{\prime} \mathrm{S}$ e longitude de $43^{\circ} 51^{\prime} \mathrm{W}$.

Os experimentos foram implantados em caixas gerbox transparentes de $11 \times 11 \times 3 \mathrm{~cm}$, preenchidas com $400 \mathrm{~g}$ de areia grossa, grãos de 1 a $3 \mathrm{~mm}$ de espessura, previamente lavada e esterilizada com água corrente deionizada e em estufa a $180^{\circ} \mathrm{C}$ por $72 \mathrm{~h}$, respectivamente. Foram colocados 10 tubérculos sadios de tiririca de tamanho médio, entre 0,4 e 1,0 g, para desenvolver em cada gerbox nos dois experimentos.

A capacidade de retenção de água da areia foi feita pelo teste de estufa. Nesse procedimento, ajustou-se a umidade desse substrato para $60 \%$ da capacidade de campo com água deionizada, aplicada junto dos tratamentos testados como veículo, formando calda herbicida, extrato ou preparado homeopático nos gerbox, de acordo com o tratamento.

Os experimentos foram conduzidos em estufa do tipo BOD a $25^{\circ} \mathrm{C}$, com fotoperiodo de 12 horas.

O primeiro experimento foi realizado com extratos aquosos de folhas frescas das plantas de capim-limão (Cymbopogon citratus, alecrimpimenta (Lippia sidoides), mucuna-preta (Stizolobium aterrimum) e feijão-de-porco (Canavalia ensiformes). Os extratos aquosos foram feitos por infusão, em que as folhas foram imersas em água à temperatura de aproximadamente $80^{\circ} \mathrm{C}$, permanecendo em repouso até atingir a temperatura ambiente (Fortes et al., 2009). Posteriormente, realizou-se a filtragem do extrato e a sua aplicação, de acordo com o tratamento, nas caixas gerbox. O extrato foi feito na concentração de $20 \%$ peso/volume.

O herbicida usado foi atrazina, na formulação comercial Atrazina Nortox $500 \mathrm{SC}^{\circledR}$, com $500 \mathrm{~g} \mathrm{~L}^{-1}$ de ingrediente ativo (Anvisa, 2009). A dose usada foi de $2,5 \mathrm{~kg} \mathrm{ha}^{-1}$ de atrazina, a qual foi ajustada para a área da superficie do gerbox, sendo aplicados $6,0 \mu 1$ por gerbox.

No segundo experimento, foi respeitada a relação de uma gota de tintura-mãe de tiririca para 99 gotas de álcool 70\%, ou seja, a escala centesimal hahnemanniana, codificada como $\mathrm{CH}$. Os medicamentos homeopáticos foram manipulados de acordo com as técnicas oficiais (Farmacopeia, 1977). A fim de garantir total imparcialidade, o experimento foi conduzido no sistema "duplo-cego", no qual os tratamentos foram codificados, ficando incógnitos aos aplicadores e avaliadores e conhecidos apenas por um pesquisador inerente ao ensaio.

Em ambos os experimentos foram avaliados número de brotações emergidas diariamente, comprimento das plântulas, massa total, massa fresca e massa seca da parte aérea e raízes, bem como o percentual de emergência após 15 dias de plantio, a viabilidade dos tubérculos após os tratamentos e o índice de velocidade de emergência das plântulas, de acordo com cada tratamento.

No teste de comprimento das plântulas foi utilizada a metodologia da AOSA (1983), a qual leva em consideração o número de plantas normais mensuradas (cm por planta normal).

Após a avaliação do comprimento, as plântulas foram divididas em parte aérea e raizes, e o material, pesado em balança de precisão (três casas decimais) para obtenção da massa fresca. Em seguida, armazenou-se o material em sacos de papel, os quais foram levados à estufa com circulação forçada em temperatura de $60^{\circ} \mathrm{C}$, até atingirem peso constante, para determinação da massa seca.

$O$ índice de velocidade de emergência foi obtido por meio de contagens diárias do número de plântulas de tiririca brotadas, assim que emergia a brotação do tubérculo, até a 
estabilização (Maguire, 1962), empregando-se a seguinte equação (Brasil, 1992):

$$
I V E=\sum\left\{\frac{E 1}{N 1}+\frac{E 2-E 1}{N 2}+\frac{E 3-E 2}{N 3} \therefore \frac{E n 2-E n 1}{N n}\right\}
$$

em que E1: número de tubérculos emergidos no primeiro dia após o início do teste; E2: número de tubérculos emergidos no segundo dia após o início do teste, e assim por diante; En1 e En2: número de tubérculos emergidos no penúltimo e no último dia do teste, respectivamente; $N 1$ e N2: número de dias após o início do teste; e $N n$ : número de dias correspondente à duração do teste.

Os tubérculos que não apresentaram brotação foram mergulhados em água por $24 \mathrm{~h}$ e, logo após, em solução aquosa de cloreto de 2,3,5-trifenil tetrazólio, a $0,5 \%$, por quatro horas a $25{ }^{\circ} \mathrm{C}$, no escuro, como descrito por Delouche et al. (1976). Após esse tratamento, os tubérculos que apresentaram coloração rósea a avermelhada pelos sais de tetrazólio foram considerados viáveis, e os demais, inviáveis. Entre os viáveis, os que apresentaram coloração rósea foram considerados normais, e os que apresentaram coloração vermelha intensa foram considerados deteriorados. Também foi avaliada a firmeza dos tubérculos, para determinar a consistência e confirmar o grau de deterioração destes.

No primeiro experimento, o delineamento experimental utilizado foi o inteiramente casualizado (DIC), com seis tratamentos e quatro repetições, os quais foram: água destilada, aplicação do herbicida atrazina e os extratos aquosos de feijão-de-porco, mucuna-preta, alecrim-pimenta e capim-limão. No segundo experimento, com homeopatia, utilizou-se o delineamento experimental inteiramente casualizado (DIC), constando de seis tratamentos: água destilada, álcool $70 \%$ e as dinamizações $3 \mathrm{CH}, 6 \mathrm{CH}, 9 \mathrm{CH}$ e $12 \mathrm{CH}$, tendo quatro repetições. Em ambos os experimentos os dados foram submetidos à análise de variância, seguida de comparação dos tratamentos pelo teste de Scott-Knott a 5\% de probabilidade.

\section{RESULTADOS E DISCUSSÃO}

No experimento com extratos de plantas, os tratamentos com alecrim-pimenta e com atrazina diminuíram significativamente o percentual de emergência, o índice de velocidade de emergência, o comprimento, a massa fresca total, a massa fresca da parte aérea, a massa fresca das raízes, a massa seca da parte aérea e a massa seca das raízes das plântulas de tiririca; sendo que o extrato de alecrimpimenta apresentou maior efeito na redução do comprimento das plântulas de tiririca que o herbicida (Tabela 1).

De acordo com Borges et al. (2004), o óleo essencial de alecrim-pimenta, na concentração de $0,25 \mathrm{ml} \mathrm{L}^{-1}$, aplicado em placa de Petri emulsionada com ricinoleato de sódio, inibiu totalmente a germinação de sementes de Emilia sonchifolia. Alves et al. (2004), avaliando a alelopatia de extratos voláteis na germinação de sementes e no comprimento da raiz de plântulas de alface, verificaram redução brusca no

Tabela 1 - Percentual de emergência (EMER), índice de velocidade de emergência (IVE), comprimento das plântulas (COMPR), massa total (MT), massa fresca da parte aérea (MFPA), massa fresca da raiz (MFR), massa seca da parte aérea (MSPA) e massa seca da raiz (MSR) de tiririca tratada com extratos de plantas e atrazina. Montes Claros-MG, 2008

\begin{tabular}{|l|c|c|c|c|r|r|r|c|c|}
\hline \multirow{2}{*}{ Tratamento } & EMER & \multicolumn{1}{|c|}{ IVE } & COMPR & MT & MFPA & \multicolumn{1}{c|}{ MFR } & MSPA & MSR \\
\cline { 2 - 9 } & $(\%)$ & (índice) & $(\mathrm{cm})$ & \multicolumn{5}{|c|}{$(\mathrm{g})$} \\
\hline Extr. capim-limão & $82 \mathrm{~A}$ & $3,24 \mathrm{~A}$ & $11,85 \mathrm{~A}$ & $3,28 \mathrm{~A}$ & $2,55 \mathrm{~A}$ & $0,735 \mathrm{~A}$ & $0,211 \mathrm{~A}$ & $0,074 \mathrm{~A}$ \\
\hline Extr. mucuna-preta & $82 \mathrm{~A}$ & $3,50 \mathrm{~A}$ & $10,47 \mathrm{~A}$ & $2,68 \mathrm{~A}$ & $2,16 \mathrm{~A}$ & $0,528 \mathrm{~A}$ & $0,204 \mathrm{~A}$ & $0,072 \mathrm{~A}$ \\
\hline Extr. feijão-de-porco & $90 \mathrm{~A}$ & $4,23 \mathrm{~A}$ & $11,58 \mathrm{~A}$ & $2,80 \mathrm{~A}$ & $2,47 \mathrm{~A}$ & $0,330 \mathrm{~B}$ & $0,234 \mathrm{~A}$ & $0,028 \mathrm{~B}$ \\
\hline Água destilada & $82 \mathrm{~A}$ & $3,14 \mathrm{~A}$ & $7,37 \mathrm{~B}$ & $1,16 \mathrm{~B}$ & $0,86 \mathrm{~B}$ & $0,296 \mathrm{~B}$ & $0,090 \mathrm{~B}$ & $0,026 \mathrm{~B}$ \\
\hline Atrazina & $62 \mathrm{~B}$ & $2,14 \mathrm{~B}$ & $7,99 \mathrm{~B}$ & $1,14 \mathrm{~B}$ & $0,89 \mathrm{~B}$ & $0,253 \mathrm{~B}$ & $0,089 \mathrm{~B}$ & $0,014 \mathrm{~B}$ \\
\hline Extr. alecrim-pimenta & $57 \mathrm{~B}$ & $1,22 \mathrm{~B}$ & $4,05 \mathrm{C}$ & $0,44 \mathrm{~B}$ & $0,38 \mathrm{~B}$ & $0,059 \mathrm{~B}$ & $0,032 \mathrm{~B}$ & $0,007 \mathrm{~B}$ \\
\hline CV (\%) & 13,01 & 35,797 & 20,86 & 34,44 & 34,24 & 47,03 & 35,78 & 54,18 \\
\hline
\end{tabular}

Médias seguidas da mesma letra maiúscula, na coluna, não diferenciam estatisticamente entre si pelo teste de Scott-Knott a $5 \%$ de probabilidade. 
percentual de germinação a partir de 0,01\% de óleo de alecrim-pimenta. Já com relação ao comprimento da raiz, o efeito inibitório ocorreu proporcionalmente ao aumento da concentração, e nas concentrações entre 0,1 e $1,0 \%$ do óleo de alecrim-pimenta não houve crescimento das raízes de plântulas de alface.

Apesar de nos trabalhos apresentados por Borges et al. (2004) e Alves et al. (2004) ter-se utilizado óleo essencial de alecrim pimenta e, neste experimento, o extrato aquoso dessa espécie medicinal, os resultados foram semelhantes, reduzindo o crescimento da tiririca e apresentando efeito fitotóxico sobre a emergência dos tubérculos e o crescimento de plântulas.

O herbicida atrazina é recomendado no controle em pré-emergência de tiririca nas culturas de cana-de-açúcar, milho e sorgo, de acordo com informações dos diferentes fabricantes (Anvisa, 2009). Entretanto, a tiririca é considerada pouco suscetível ao atrazina quando da sua aplicação em pré-emergência, o que é comum em se tratando da maioria dos produtos usados nessas condições para o manejo dessa espécie daninha (Lorenzi, 2000). Quanto à eficiência do atrazina, Cordeiro et al. (2006), avaliando a eficiência da mistura nicosulfuron + atrazina aplicada em pós-emergência do milho, na concentração de $40 \mathrm{~g} \mathrm{~L}^{-1}$ e dose de $1,0 \mathrm{~L} \mathrm{ha}^{-1}$ e concentração de $500 \mathrm{~g} \mathrm{~L}^{-1}$ e dose de 3,0 L ha-1, respectivamente, no controle de tiririca, observaram alta eficiência deste tratamento (controle e" 95\%) para todas as espécies infestantes da área, com exceção de $C$. rotundus, que mostrou controle regular (80\%). Apesar de a eficiência de controle da parte aérea de $C$. rotundus pelos herbicidas aplicados (nicosulfuron + atrazina) ter sido similar em ambos os sistemas de manejo do solo, os autores relatam a alta reinfestação da área de preparo convencional. Isso foi ocasionado pelo fato de os produtos utilizados não exercerem atividade herbicida capaz de eliminar as rebrotas dos tubérculos. No presente estudo, o extrato aquoso de alecrimpimenta seria uma alternativa ao uso de herbicidas no manejo da tiririca em agricultura orgânica, apesar de serem necessários mais estudos para esse fim.

Tubérculos tratados com água destilada apresentaram maior percentual de emergência e maior índice de velocidade de emergência quando comparados àqueles expostos ao extrato de alecrim-pimenta e com atrazina, não havendo diferenças para as demais variáveis.

Plântulas oriundas de tubérculos tratados com extrato de alecrim-pimenta, atrazina, água destilada e extrato de feijão-de-porco apresentaram menor massa de raízes frescas e secas do que os tratamentos com extrato de mucuna-preta e capim-limão. Por outro lado, mostraram maior emergência e maior índice de velocidade de emergência os tratamentos com extratos de feijão-de-porco, mucuna-preta e capim-limão, bem como o tratamento com água destilada, usado como testemunha (Figura 1).

Segundo Carvalho et al. (2002), o extrato aquoso da parte aérea da mucuna-preta proporcionou redução no crescimento, estabilização na multiplicação de tubérculos e menor indice de velocidade de emergência da tiririca, sendo esses menores que os da testemunha com água deionizada.

Neste trabalho, os extratos aquosos de mucuna-preta, feijão-de-porco e capim-limão não apresentaram redução do crescimento nem estabilização na multiplicação dos tubérculos e, ainda, proporcionaram maiores índices de velocidade de emergência e maior percentual de emergência que os demais tratamentos, apresentando assim efeito alelopático benéfico em tubérculos de tiririca. Esses resultados foram semelhantes aos observados por Carvalho et al. (2002) com extrato aquoso de feijão-de-porco e no estudo realizado por Fontanétti et al. (2007), onde os autores não encontraram efeito do cultivo de mucunapreta, feijão-de-porco e crotalária no manejo da tiririca.

Plântulas de tiririca oriundas de tubérculos tratados com extratos de capim-limão, feijão-de-porco e mucuna-preta mostraram maior comprimento que aquelas expostas a atrazina, alecrim-pimenta e água destilada.

Quanto ao teste de viabilidade, foi observado que a maioria dos tubérculos que não emergiram estavam viáveis (Tabela 2) e, provavelmente, dormentes - característica comum à espécie (Jakelaitis et al., 2003). Essa dormência dos tubérculos de tiririca causou um aumento no coeficiente de variação 


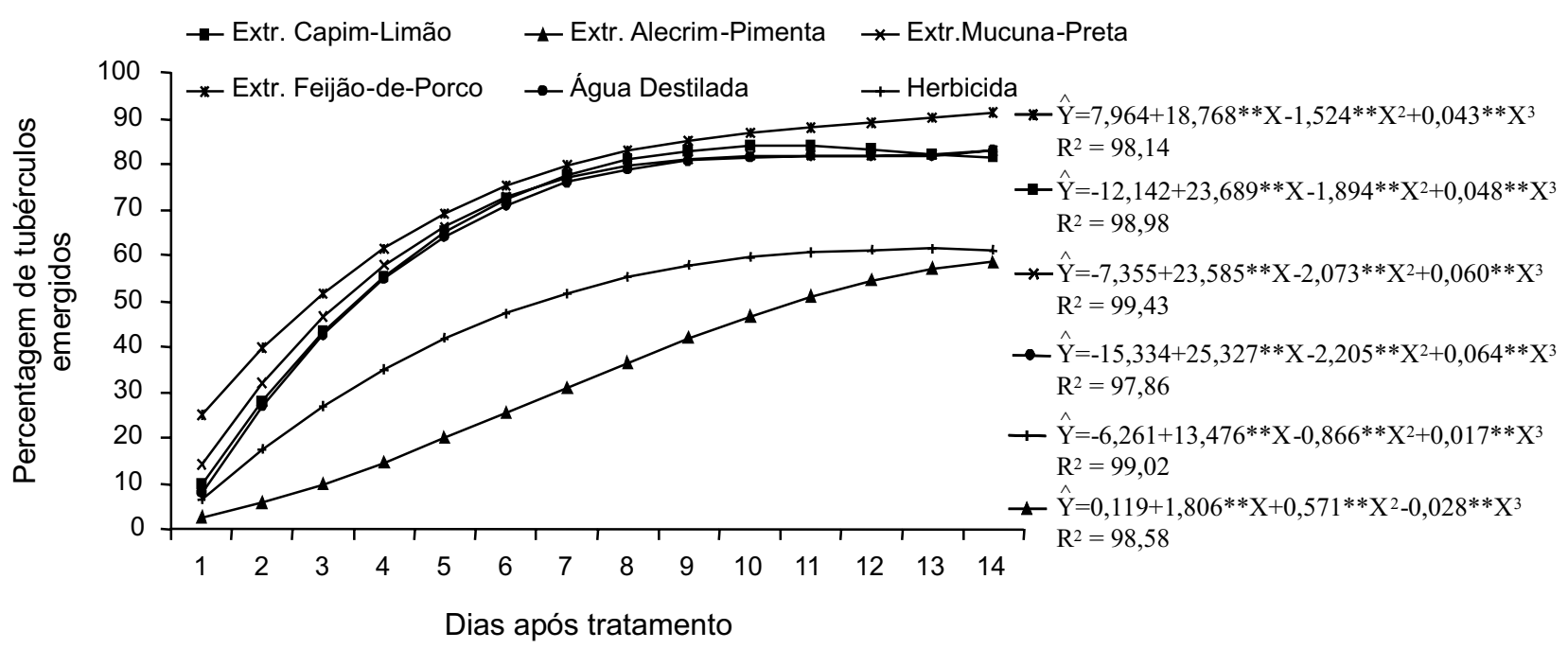

Figura 1 - Velocidade de emergência da tiririca tratada com extratos de capim-limão, alecrim-pimenta, mucuna-preta e feijão-de-porco, usando água destilada como controle negativo e herbicida atrazina como controle positivo. Montes Claros-MG, 2008.

Tabela 2 - Número de tubérculos que não emergiram (N EMER), número de tubérculos viáveis (viáveis), número de tubérculos inviáveis (inviáveis), número de tubérculos considerados normais (normais) e número de tubérculos com avançado grau de deterioração (deteriorados) após tratamento com extratos de plantas. Montes Claros-MG, 2008

\begin{tabular}{|l|c|c|c|c|c|}
\hline \multicolumn{1}{|c|}{ Tratamento } & N EMER & Viáveis & Inviáveis & Normais & Deteriorados \\
\hline Extr. capim-limão & 7 & 7 & 0 & 6 & 1 \\
\hline Extr. alecrim-pimenta & 17 & 17 & 0 & 13 & 4 \\
\hline Extr. mucuna-preta & 7 & 7 & 0 & 6 & 1 \\
\hline Extr. feijão-de-porco & 5 & 5 & 0 & 5 & 0 \\
\hline Água destilada & 7 & 6 & 1 & 6 & 0 \\
\hline Atrazina & 14 & 14 & 0 & 10 & 4 \\
\hline
\end{tabular}

do trabalho. Em trabalhos futuros, deve-se aumentar o número de tubérculos por parcela ou o número de repetições, para evitar esse coeficiente de variação alto. Os tratamentos com extrato de alecrim-pimenta e herbicida foram os que mostraram maior número de tubérculos que não emergiram e que possuíam maior número de tubérculos com avançada deterioração, apesar de a maioria dos tubérculos que não emergiram (mais que $70 \%$ ) se apresentaram viáveis.

No experimento com homeopatia, as variáveis índice de velocidade de emergência, comprimento das plântulas, massa total, massa fresca da parte aérea, massa fresca da raiz, massa seca da parte aérea e massa seca da raiz de tiririca tratada com homeopatia não diferenciam estatisticamente entre si pelo teste de Scott - Knott a 5\% de probabilidade.

A única variável que apresentou diferença estatística entre os tratamentos com homeopatia foi a emergência; os tratamentos com água destilada, álcool a $70 \%$ e dinamização $6 \mathrm{CH}$ apresentaram menor percentual de emergência: 75,80 e $80 \%$, respectivamente, em relação às dinamizações $3 \mathrm{CH}, 9 \mathrm{CH}$ e $12 \mathrm{CH}$, com 87,90 e $97 \%$ respectivamente.

A dinamização $6 \mathrm{CH}$ apresentou alto percentual de tubérculos emergidos (80\%) e alto indice de velocidade de emergência $(2,63)$, o que não garante o bom manejo da tiririca. Rossi et al. (2007) indicam o decréscimo de 
aproximadamente $35 \%$ da massa seca da tiririca quando da aplicação de 50 e $500 \mathrm{~g}_{\text {ha }}{ }^{-1}$ do preparado homeopático. Em outro experimento, Rossi et al. (2005) não encontraram variações significativas na massa seca da parte aérea da tiririca em relação às testemunhas com a aplicação dos preparados homeopáticos nas dinamizações $3 \mathrm{CH}, 6 \mathrm{CH}, 9 \mathrm{CH}, 12 \mathrm{CH}$, $15 \mathrm{CH}$ e $18 \mathrm{CH}$. Esses resultados coincidem com os obtidos neste trabalho.

A maioria dos tubérculos tratados com homeopatia que não emergiram apresentaramse viáveis (Tabela 3). O tratamento com água destilada mostrou o maior número de tubérculos que não emergiram e com alto grau de deterioração. O tratamento $12 \mathrm{CH}$ apresentou o maior número de tubérculos emergidos e nenhum tubérculo deteriorado.

Tabela 3 - Número de tubérculos que não emergiram (NEMER), número de tubérculos viáveis (viáveis), número de tubérculos inviáveis (inviáveis), número de tubérculos considerados normais (normais) e número de tubérculos com avançado grau de deterioração (deteriorados) após tratamento com homeopatia. Montes Claros-MG, 2008

\begin{tabular}{|l|c|c|c|c|c|}
\hline Tratamento & N EMER & Viáveis & $\begin{array}{c}\text { Inviá- } \\
\text { veis }\end{array}$ & Normais & $\begin{array}{c}\text { Dete- } \\
\text { riorados }\end{array}$ \\
\hline $3 \mathrm{CH}$ & 5 & 5 & 0 & 3 & 2 \\
\hline Álcool $70 \%$ & 8 & 8 & 0 & 6 & 2 \\
\hline $6 \mathrm{CH}$ & 8 & 7 & 1 & 5 & 2 \\
\hline $12 \mathrm{CH}$ & 1 & 1 & 0 & 1 & 0 \\
\hline $9 \mathrm{CH}$ & 4 & 4 & 0 & 3 & 1 \\
\hline Água destilada & 9 & 9 & 0 & 6 & 3 \\
\hline
\end{tabular}

Os estudos realizados sinalizam o uso do extrato de alecrim-pimenta como forma alternativa promissora no manejo de tiririca. Devem-se estudar com mais detalhes os mecanismos físiológicos envolvidos e as substâncias com efeito herbicida presente nessa planta. Por outro lado, a homeopatia não apresentou efeito significativo para o manejo da tiririca.

\section{AGRADECIMENTOS}

Ao Programa de Educação Tutorial, PET/ SESu do ICA/UFMG, pela concessão de bolsa de estudo.

\section{LITERATURA CITADA}

ALVES, M. C. S. et al. Alelopatia de extratos voláteis na germinação de sementes e no comprimento da raiz de alface. Pesq. Agropec. Bras., v. 39, n. 11, p. 1083-1086, 2004.

ANVISA. Relatório do agrotóxico. Disponível em: $<\mathrm{http} / /$ www4.anvisa.gov.br/AGROSIA/asp/frm_dados_agrotoxico $>$. Acesso em: 14 de Agosto de 2009.

ASSOCIATION OF OFFICIAL SEED ANALYSTS - AOSA. Seed vigor testing handbook. East Lansing: 1983. 93 p.

BALBINOT Jr., A. A. Manejo das plantas daninhas pela alelopatia. Agropec. Catarinense, v. 17, n. 1, p. 61-64, 2004

BORGES, N. S. S. et al. Óleos essenciais de capim citronela e de alecrim pimenta na germinação de sementes de Emilia sonchifolia, (L.) D.C. In: CONGRESSO BRASILEIRO DE OLERICULTURA, 44., 2004, Campo Grande. Anais... Campo Grande: 2004. p. 1-6.

BRASIL. Ministério da Agricultura e da Reforma Agrária. Regras para análise de sementes. Brasília: SNDA/DNDV/ CLAV, 1992. 365 p.

CARVALHO, G. J.; FONTANÉTTI, A.; CANÇADO, C. T. Potencial alelopático do feijão-de-porco (Canavalia ensiformes) e da mucuna-preta (Stizolobium aterrimum) no controle da tiririca (Cyperus rotundus). Ci. Agrotecnol., v. 26, n. 3. p. $647-651,2002$

CORDEIRO, L. A. M. et al. Efeito do plantio direto no controle de tiririca (Cyperus rotundus L.) e outras plantas daninhas na cultura do milho. R. Bras. Herbic., v. 5, n. 1, p. 1-9, 2006.

CRUZ, M. E. S. et al. Efeito alelopático de Cymbopogon citratus e Artemisia absinthium sobre sementes de Bidens pilosa. Acta Hortic., n. 569, p. 229-233, 2002.

DELOUCHE, J. C. et al. O teste de tetrazólio para viabilidade da semente. Brasília: AGIPLAN, 1976. 103 p.

FARMACOPÉIA HOMEOPATIA BRASILEIRA. São Paulo: Andrei, 1977. 115 p.

FONTANÉTTI, A. et al. Efeito alelopático da adubação verde no controle de tiririca (Cyperus rotundus L.). R. Bras. Agroecol., v. 2, n. 1, p. 1365-1368, 2007.

FORTES, A. et al. Efeito alelopático de sabugueiro e capimlimão na germinação de picão-preto e soja. Acta Cientiarum Agronomy, v. 31, n. 2, p. 241-246, 2009.

GOMIDE, M. B. Potencialidades alelopáticas dos restos culturais de dois cultivares de cana-de-açúcar (Saccharum sp.), no controle de algumas plantas daninhas. 1993. $96 \mathrm{f}$. Tese (Doutorado em Fitotecnia) - Escola Superior de Agricultura Luiz de Queiroz, Piracicaba, 1993.

Planta Daninha, Viçosa-MG, v. 28, n. 3, p. 499-506, 2010 
JAKELAITIS, A. et al. Effects of management systems on purple nutsedge populations (Cyperus rotundus). Planta Daninha, v. 21, n. 1, p. 89-95, 2003.

LORENZI, H. Manual de identificação e controle de plantas daninhas. 2.ed. São Paulo: Instituto Plantarum, 2000. 339 p.

MAGALHÃES, A. C.; FRANCO, C. M. Toxidade de feijão de porco sobre a "tiririca". Bragantia, v. 21, n. 35, p. 53-58, 1962.

MAGUIRE, J. D. Speed of germination-aid in selection evaluation for seedling emergence and vigour. Crop Sci., v. 2, p. 176-199, 1962.

PANOZZO, L. E. et al. Métodos de manejo de cyperus esculentus na lavoura de arroz irrigado. Planta Daninha, v. 27 , n. 1 , p. $165-174,2009$
ROSSI, F. et al. Aplicação de preparado homeopático no controle da Tiririca em área agroecológica. R. Bras. Agroecol., v. 2 , n. 1, p. $870-873,2007$.

ROSSI, F et al. Aplicação de nosódios visando o equilíbrio do desenvolvimento da tiririca (CYPRO). In: CONGRESSO BRASILEIRO DE AGROECOLOGIA, 3., SEMINÁRIO ESTADUAL DE AGROECOLOGIA, 2005, Florianópolis. Anais... Florianópolis: 2005

ROSSI, F. et al. A ciência da homeopatia na olericultura Hortic. Bras., v. 2, n. 2, p. 1-8, 2004

SAITO, L. M. As plantas praguicidas: alternativa para o controle de pragas da agricultura. Jaguariúna: Embrapa Meio Ambiente, 2004

SOUZA FILHO, A. P. S.; RODRIGUES, L. R. A.; RODRIGUES, T. J. D. Potencial alelopático de forrageiras tropicais: efeitos sobre invasoras de pastagens. Planta Daninha, v. 15, n. 1, p. 53-60, 1997. 